\title{
¡NO MÁS PRINCESAS! REFLEXIÓN DE ALGUNAS TEORÍAS EN LA ENSEÑANZA DEL AMOR ROMÁNTICO DE LA LITERATURA EN LA VIDA DE LOS JÓVENES ACTUALES DESDE UNA PERSPECTIVA DE GÉNERO
}

\author{
NO MORE PRINCESSES! REFLECTION OF SOME THEORIES IN THE \\ TEACHING OF THE ROMANTIC LOVE OF LITERATURE IN THE LIFE OF \\ THE CURRENT YOUNG PEOPLE FROM A GENDER PERSPECTIVE
}

\section{Juan Pablo MARCOLETA HARDESSEN \\ Universidad Autónoma de Barcelona jpmarcoleta@hotmail.com}

Resumen: El presente trabajo es una reflexión de diversas teorías (sociológicas, psicológicas, económicas y/o sociales) en la enseñanza del amor romántico de la literatura hacia los jóvenes de hoy, con la finalidad de erradicar la preservación de estereotipos que inducen a una diferenciación genérica que promueven la supremacía masculina y el control femenino.

Palabras clave: teorías, amor romántico, jóvenes, literatura, género

Abstract: This paper is a reflection of various theories (sociological, psychological, economic and / or social) in the teaching of romantic love of literature to young people today, with the aim of eradicating the preservation of stereotypes that induce a generic differentiation that promote male supremacy and female control.

Keywords: theories, romantic love, youth, literature, gender. 
¡No más princesas! Reflexión de algunas teorías en la enseñanza del amor romántico...

$\mathrm{P}$ retender recordar con precisión desde cuándo hablamos de amor romántico sería caer en una búsqueda innecesaria; resulta más interesante detenerse en sus consecuencias. Si bien no es complejo revisar algunos libros de historia -o literatura, o de historia de la misma- parece mejor retomar el recuerdo que hace Coral Herrera (2010) en que esta visión romántica del amor proviene aproximadamente desde el siglo XI con los trovadores provenzales, siendo -se supone- una evolución del amor cortés. Se destaca esta idea de la supuesta evolución ya que, en definitiva, no sería otra cosa que un romanticismo excesivo, una exacerbación de la imagen de la mujer y, particularmente, de la enamorada como objetivo a alcanzar y meta a lograr; vale decir, la búsqueda de una conquista como si de un trofeo o un territorio se tratase. Y esto no parece evolución.

$\mathrm{Al}$ apreciarse este romanticismo excesivo se cae en la cuenta, inevitable, que tras todo exceso habrá consecuencias que sobrellevar. Y cuáles son esas consecuencias: en la promoción del amor romántico resaltamos la imagen de príncipes y princesas, promoviendo el invencible masculino y la débil femenina; un príncipe -azul- que conquistará a una princesa -rosa-, elementos que contribuyen al fomento de estereotipos - precisamente como aquel que los niños visten de azul y las niñas de rosa-, al abuso de imagen - del cuerpo- y del control femenino, transformándose en un comportamiento de siglos, en una conducta aprendida y heredada por generaciones y que al día de hoy ha terminado hartando a parte de una sociedad como la actual; sociedad que debiese pedir a gritos lo que pretende el título del presente trabajo: ¡No más princesas!

Pese al ahínco, esta idea no es nueva. Ya antes lo había mencionado sabiamente Gabriela Mistral en sus famosos -y asertivos- versos del poema tan idóneamente titulado "Miedo" (1924): «Yo no quiero que a mi niña / me la vayan a hacer princesa».

Durante siglos hemos concebido la imagen de caballeros y princesas, de reyes y sus mujeres o de jóvenes donceles en necesidad de una hembra que los acompañe, que dé crédito a su virilidad y fortaleza a su masculinidad, además de la debida descendencia. Es por ello que sobre la base de estos tantos siglos de cimientos culturales -y de comportamiento social-, es decir, de toda una vida, es que se han desarrollado diversas teorías de muy distinta índole, a saber: psicológicas, evolutivas, económicas, sociológicas; y que -isorpresa!- han dado sustento al quehacer del Hombre.

Los objetivos que se proponen para el siguiente trabajo de reflexión tienen relación con:

a) Reflexionar sobre algunas -y diversas- teorías que dan cabida a la desigualdad de género existente, sobreponiendo la figura de uno (masculino) por sobre el otro (femenino).

b) Reconocer cómo la figura de la princesa se ha transformado en una forma de control e injusticia social y cómo nos hemos apropiado de esta faceta caballeresca en diferentes manifestaciones artísticas: cine, teatro y, lo que nos convoca, literatura. 
Aunque debiese incorporar de inmediato la letra c) para el siguiente objetivo, resulta necesario apartarse de esta idea central y expresar el ferviente deseo de querer cumplir con:

c) Pretender -y seguir avanzando en- erradicar el estereotipo de la princesa; también conocida como "mujer macetero" o "mujer ornamento", en virtud de las relaciones -de parejas- en dependencia, sujeción a un marido como proyecto de vida, sumisión de pareja, búsqueda de marido como objetivo de vida, que deriva en control de la relación, violencia doméstica y un sinfín de abusos que se han hecho público en noticieros en relación a violaciones, maltratos y una cada vez más alta tasa de femicidios.

Para procurar el cumplimiento de estos objetivos «hay que preguntarse, en efecto, cuáles son los mecanismos históricos responsables de la deshistoricización y de la eternización relativas de las estructuras de la división sexual y de los principios de división correspondientes» (Bourdieu, 2000, pp. 7-8), así como también hay que reconocer la estructura de supremacía social que se ha hecho imperar en todos estos decenios. Ahora bien, si es sobre la base de esta estructura ideológica establecida por siglos que enseñamos a nuestros jóvenes, no pretendamos producir cambios sociales si no sabemos leer críticamente.

Es de conocimiento que los jóvenes, en la vida y en la escuela, viven un proceso de cambios físicos y psicológicos feroz, por tanto, es preciso saber a quiénes tenemos en frente. Adrián y Rangel (s/a), en su artículo “Aprendizaje y desarrollo de la sociedad”, plantean que los jóvenes quinceañeros son ya, en lo fundamental, individuos adultos biológicamente, pero en ningún caso ni psicológica ni socialmente. Es más, este desfase puede prolongarse al menos entre cinco y diez años, vale decir, si hablamos de jóvenes quinceañeros, podríamos extender este período incorporando esos cinco o diez; en suma: pudiendo llegar, incluso, a los veinte o veinticinco años. Lo anterior nos hace ver que niños y niñas que se van haciendo adultos aprenden - al menos en esta etapa- mientras cursan los años de secundaria y, pudiendo también hacerlo, cuando egresan de ella, sea en la universidad o centros de estudios superiores. En definitiva, el objetivo de este párrafo es reconocer el acervo que aprendemos y heredamos desde siglos y la relación que puede establecerse en el proceso de aprendizaje de los jóvenes.

A través de diversas áreas teóricas podemos apreciar lo siguiente: desde la psicología podemos considerar que para G. Stanley Hall, reconocido psicólogo y pedagogo, la adolescencia es un período de «tormenta y estrés», que es una expresión tomada, precisamente, de la literatura romántica alemana. Cómo no considerar, por ejemplo, obras como Las desventuras del joven Werther (1774), donde un enamorado empedernido sufre en estas relaciones idealizadas el romanticismo excesivo y que culmina con el trágico suicido. Incluso, podríamos remontarnos al popular Romeo y Julieta (1597), famosa historia de jóvenes enamorados que transcurre en tres días y que consuma seis muertos.

Por su parte, desde el psicoanálisis es similar la consideración que la adolescencia es el «resultado del brote pulsional que se produce por la pubertad (etapa genital), que altera el equilibrio psíquico alcanzado durante la infancia (etapa de latencia). Este desequilibrio incrementa el grado de 
vulnerabilidad del individuo y puede dar lugar a procesos de desajuste y crisis, en los cuales están implicados mecanismos de defensa psicológicos (fundamentalmente la represión de impulsos amenazantes) en ocasiones inadaptativos» (Freud, 2013, p. 10), es decir, se confirma y reitera $-\mathrm{y}$ debiese despertarnos- acerca de este proceso y período tormentoso y estresante.

¿Qué relación tiene esto con el amor romántico? La literatura que presenta las características del amor romántico ha servido de sustento para la formación, lectura o aprendizaje de varias generaciones de jóvenes y resulta ser, al día de hoy, una invitación para ser leída con otros ojos. Así tenemos: Piaget (1947) consideraba que la infancia del individuo juega un papel vital y activo con el crecimiento de la inteligencia, y que el niño aprende a través de hacer y explorar activamente; y ese hacer y explorar activamente está estrechamente relacionado con revisar, por ejemplo, las relaciones de pareja que se establecen en la literatura, que se han establecido a través de siglos junto a los problemas sociales que pueden apreciarse hoy en día -en prensa escrita o televisión- como aquellos descritos más arriba: relaciones de dependencia, sujeción a un marido como objetivo de vida, sumisión de pareja, control de pareja, violencia doméstica, asesinatos, etc.

Un buen ejemplo a considerar: circula libre la creación de un cibernauta que modificó el título de unos clásicos de Disney para hacernos ver el trasfondo que subyace no sólo en Disney mismo, sino en los clásicos de la literatura en general. Si bien en la red está disponibles en imágenes, aquí sólo se expresarán los títulos por cuestión de formato. A saber: de la famosa historia de La bella y la bestia podríamos entenderla, leerla o releerla como el Síndrome de Estocolmo, donde una bella y angelical princesa se enamora de un ser en apariencia bestial o de un comportamiento que se podría traducir como tal. De la popular historia de La Cenicienta, también llevada al cine en forma animada, podríamos leer Los cambios de imagen solucionan todo. O, en un tercer ejemplo, de la película $L a$ Sirenita o Ariel-según su traducción- podría ser: Cambia por tu hombre.

Revisar estos ejemplos de clásicos y el trasfondo que alguien pudo leer en ellos nos permite abrir los ojos y ver, minuciosamente, la forma - o la lectura- que puede hacerse de los clásicos, o de la literatura en general, en los tiempos que corren actualmente. No estamos en la época del amor romántico, no estamos en tiempos del excesivo romanticismo como una forma de subyugar; sin embargo, pareciese que se aplica. Estamos Leyendo con los mismos ojos de antaño. Hoy estamos en tiempos de igualdad, estamos en tiempos de promover la equidad de género y de enseñar a hombres y mujeres -y a nuestros jóvenes-, a través de la literatura entre otras herramientas, que ya no vivimos tiempos de princesas. La vida -y las teorías- se han construido con ojos masculinos.

Desde las teorías sociológicas, considerando la teoría de sistemas o teorías del conocimiento en diversas áreas (ciencia, lenguaje, lógica, teoría del comportamiento, ética) se aprecia del mismo modo la supremacía masculina apartando estas teorías de la idea de igualdad de género, lo que contribuye a una enseñanza en jóvenes segregada y sexista. María Ángeles Durán (1996) plantea que recién en 1979 aparecería un libro que se titulaba Liberación y Utopía; que consistía en ser una obra colectiva sobre la mujer y la ciencia, en la que da cabida a su triple acción: la mujer como sujeto de conocimiento (investigadora o creadora), como objeto de indagación científica y como usuaria, receptora o 
transmisora de los contenidos de la ciencia. Esta idea de la mujer en la ciencia ya reconocemos que puede aplicarse a los más variados ámbitos intelectuales: sociología, filosofía, lingüística, psicología, historia, geografía, derecho, economía, biología y medicina. Lo anterior ratifica el peso de la herencia y confirma la intención de la validez e importancia de una enseñanza en igualdad de género y de condiciones. En este sentido, «la incorporación masiva de mujeres a la investigación trae consigo la reconsideración de la tradicional asociación de ideas entre masculinidad, objetividad, ciencia y poder por una parte y feminidad, subjetividad, sentimentalidad, naturaleza y amor, por otra» (Durán, 1996, p. 5); vale decir, una mirada reconstructiva del príncipe o caballero, objetivo y poderoso, ante la princesa emocional, débil y conquistable.

Estas reflexiones acerca del amor romántico -y de no querer más princesas-apuntan a la idea de desarrollar el espíritu crítico de los jóvenes en la desaparición de supuestos instalados en el inconsciente colectivo de una supremacía intelectual inexistente, donde el hombre es el ser racional pensante y la mujer el ser sentimental espiritual dominable. Estas reflexiones reconocen, a su vez, que la única supremacía masculina -histórica- ha sido en torno al poder.

Bajo esta premisa de reflexión de teorías, desde el área política, Enguita (1996) en su artículo "El marxismo y las relaciones de género" deduce que mientras Marx hablaba de luchas de clases y sociedad en general, olvidaba a la mujer en particular. De estos fenómenos sociales -y políticos- es imposible olvidar toda la fuerza que carga consigo la Revolución Francesa, donde las premisas de libertad, fraternidad y -modifico- casi igualdad, removieron al mundo entero. En este aspecto, cómo olvidar que bajo la pluma de Olympe de Gouges (1791) aparece la Declaración de los Derechos de la Mujer y la Ciudadana en abierta oposición a su símil masculino.

Asimismo, puede tomarse la apreciación de Luhmann (1985), quien consideró que el amor no es en sí mismo un sentimiento, sino más bien lo vislumbra como un medio de comunicación que permite comprender las relaciones entre los medios de comunicación y las estructuras de la sociedad, vale decir, una visión política. Y ya hemos dado cuenta acerca de quién ha controlado la política.

Por su parte, Jesús Miguel (1996) estudiando a George Simmel, cita de éste: “Con la excepción de muy pocas áreas, nuestra cultura objetiva es fundamentalmente la del varón. Son los varones quienes han creado el arte y la industria, la ciencia y el comercio, el estado y la religión" (Simmel, citado por Miguel, 1996, p. 60). Es decir, una supremacía opresora que, según Simmel (1988), relega el rol de la mujer. Es evidente que bajo esa predominancia histórica no podemos hablar de equidad, sin embargo, sí podemos incentivar la mirada crítica de lo hasta ahora construido, en fomento de una nueva cimentación.

Si bien se mencionó con anterioridad que estos deseos de desarrollar la mirada crítica en virtud de la igualdad no son nuevos, podemos retomar las palabras del mismo Simmel (1988) en cuanto al interés de éste en legitimar una cultura femenina autónoma. Él, en particular, no habla estrictamente de princesas, no obstante, sí lo hace respecto de la independencia femenina; en suma, se alude a la misma importancia de fondo. Es más, una de las formas de relegar ese rol de la mujer es proyectando un control en áreas que no pareciesen tener relación, por ejemplo, planteando que «el único medio de 
disminuir el número de suicidios causados por la anomia conyugal es hacer más indisoluble el matrimonio» (Durkheim, 1897, p. 226); es decir, puedo aprovechar la capacidad -y la teoría- de asociar la disminución de los suicidios con una forma de control hacia la mujer.

En estas reflexiones de teorías políticas, sociales o económicas, hay que reconocer que incluso:

Las teorías psicológicas han contribuido también a esa construcción social de las mujeres como seres emocionales que impera en nuestra sociedad, un tratamiento cultural y moral con influencia directa en la socialización diferenciada de hombres y mujeres, que alcanza a esferas diversas pero relacionadas, como la maternidad o la atención a los otros, y que ha sido considerada por el feminismo como una forma de relegar a las mujeres a posiciones subordinadas (Esteban \&Távora, 2008, p. 61)

Para ir cerrando las ideas de acuerdo a los objetivos planteados, cabe determinar que se ha reflexionado sobre algunas -y diversas- teorías que dan "cabida" a la desigualdad de género existente, sobreponiendo la figura del masculino por sobre el femenino; asimismo se ha reconocido cómo la figura de la princesa se ha transformado en una forma de control e injusticia social y cómo nos hemos apropiado de esa hegemonía caballeresca en diferentes manifestaciones artísticas como el cine de Disney, el teatro de Shakespeare o la literatura de los clásicos. Lo anterior, respecto de los dos primeros objetivos planteados.

Sin embargo, respecto del tercer objetivo planteado hay algo más que decir. Sobre la base del deseo de erradicar o pretender terminar con estos estereotipos, surge así una propuesta o, más bien, una proyección: una de las formas de ir poniendo fin a este comportamiento cimentado por la herencia cultural es mirar aquella literatura clásica, principesca o de sumisión genérica con los ojos de la actualidad, del mismo modo como puede hacerse con otras manifestaciones artísticas. Para ello, sería valioso tener en consideración ciertos aspectos a desarrollar en la escuela. Así como un grupo musical argentino - Los fabulosos Cadillacs- se anima a cantar que "En la escuela nos enseñan a memorizar fechas de batallas / pero qué poco nos enseñan de amor", también podríamos animarnos a mirar hacia la escuela. Onrubia (1997) en "El papel de la escuela en el desarrollo adolescente", propone un desarrollo de formas de pensamiento con mayor nivel de abstracción, más potentes y descontextualizadas para el análisis y comprensión de la realidad (pensamiento formal), llevándolo a casos concretos. De ello, un ejemplo: en dicha propuesta, existe el apartado de Revisión y construcción de la propia identidad personal, poniendo énfasis en:

a) Revisión de la propia imagen corporal.

b) Revisión del autoconcepto y la autoestima.

c) Establecimientos de compromisos vocacionales, profesionales, ideológicos y sexuales.

Tales parámetros son perfectamente "aplicables" a través del tratamiento enseñanza-aprendizaje de la literatura, sean estos clásicos o no.

Es válido mencionar también que, para establecer cambios, es necesario dar una mirada en la escuela misma, en la psicología de los adolescentes y en la cultura diaria que se establece, porque:

De todos los factores de cambio, los más importantes son los que están vinculados a la transformación decisiva de la función de la institución escolar en la reproducción de la diferencia entre los sexos, como el 
aumento del acceso de las mujeres a la instrucción y, correlativamente, a la independencia económica, y la transformación de las estructuras familiares (Bordieu, 2000, p. 112)

Y una de las formas de empezar por aquella modificación es, precisamente, aquellas asignaturas que tienen relación con la literatura; aquellas que ven, a través de los libros y las historias, una forma de proyectar la realidad. De esta manera, podemos mirar los libros de ayer con los ojos de hoy y fortalecer esas concepciones de autoestima para desarrollar una mejor sociedad, fomentar la desaparición de estos estereotipos que ayudan a la inequidad y al control social de las mujeres, creando falsas imágenes de superioridad en jóvenes y niños: elementos que no contribuyen en una sociedad igualitaria y equitativa; en una sociedad actual. En definitiva, la literatura ha acompañado al ser humano desde siempre, es una herramienta y un medio que contiene la exquisitez de la estética y que, por su parte, puede leerse con ojos críticos y constructivos. Podríamos decir que, si bien los objetivos se cumplen momentáneamente, éstos sirven para continuar desarrollándolos.

Enseñar acerca del amor romántico tiene hoy -y debe tener de aquí en adelante- una faceta justa, que vaya en pro de una sociedad con mirada feminista, puesto que el feminismo es, en su esencia, eso: justicia social.

En un párrafo anterior se hizo mención acerca de unas imágenes libres que circulan por la red. Recogemos una de ellas para plasmar, de manera muy gráfica, la intensidad del estereotipo grabado a sangre y a fuego en el inconsciente colectivo. Dice más o menos así: Cuando el hombre espera a la mujer perfecta, la culpa es de Playboy (imagen viva de la búsqueda y satisfacción en la perfección corporal, sólo para su utilización); mientras que cuando la mujer espera al hombre perfecto la culpa es de Disney (imagen viva del príncipe protector y proveedor de seguridad. Y control).

En cierto aspecto -y aunque con múltiples lecturas- la popular cadena Netflix se ha animado a promover una serie relativamente nueva llamada (Des)encanto, escrita de esa manera, con paréntesis incluidos, pues contextualiza en una época medieval -también la viva imagen de princesas y castillosa la hija de un rey, una princesa, que rompe con estos estereotipos, trasladando aquella ambientación a una mirada actualizada de la realidad. Las actitudes de este personaje se proponen carente de toda ortodoxia o, del mismo modo, muy poco clásicas, así tenemos: eructa, bebe cerveza como si no fuese una dama, no desea casarse, se viste de manera desaliñada y todo ese tipo de cualidades que no parecen de una heredera a la corona ${ }^{1}$.

Esos cambios de paradigma dan pie para, quizás, el desarrollo de un próximo estudio. Sería igual de interesante que a partir del análisis de estas diversas teorías en torno al amor romántico y de este tipo de trabajos, en un futuro cercano, pueda surgir una nueva teoría de amor literario, acorde a los tiempos que se viven -y que se promueven-.

\footnotetext{
${ }^{1}$ Más de alguno podría pensar críticamente que esa figura femenina, en vez de romper esquemas, podría caer en una especie de masculinización del personaje... y puede ser. Sin perjuicio de lo anterior, aquella interesante reflexión da cabida a otros tipos de trabajos que, ojalá, se desarrollen a futuro.
} 
¡No más princesas! Reflexión de algunas teorías en la enseñanza del amor romántico...

\section{Referencias}

ADRIÁN SERRANO, Julián - RANGEL GASCÓ, Esperanza (s/a) “Aprendizaje y desarrollo de la personalidad", pp. 1-16, en: https://www3.uji.es/ betoret/Instruccion/Aprendizaje\%20y\% 20DPersonalidad/Curso\%2012-13/Apuntes\%20Tema\%201\%20La\%20transicion\%20adolescen te\%20y\%201a\%20educacion.pdf (12/08/18).

BOURDIEU, Pierre (2000) La dominación masculina, (1. ${ }^{\mathrm{a}}$ ed. 1998, du Seuil, París), traducción Joaquín Jordá, Barcelona: Anagrama.

DURÁN, M. a Ángeles (1996) "Mujeres y hombres en el futuro de la ciencia”, en Mujeres y hombres en la formación de la teoría sociológica, Colección Academia, Madrid: Centro de Investigaciones Sociológicas.

DURKHEIM, Emile (1897) El suicidio, disponible en: http://biblio3.url.edu.gt/Libros/2012/LYM/ los_FESociales.pdf (15/03/19).

ENGUITA, Mariano (1996) "El marxismo y las relaciones de género" en Mujeres y hombres en la formación de la teoría sociológica, Colección Academia, Madrid: Centro de Investigaciones Sociológicas.

ESTEBAN, Mariluz - TÁVORA, Ana (2008): “El amor romántico y la subordinación social de las mujeres: revisiones y propuestas", Anuario de Psicología, 38/1.

FREUD, Sigmund (2013) "Esquema del psicoanálisis”, en Obras completas (José Luis Etcheverry, trad.). XXIII - Moisés y la religión monoteísta, Esquema del psicoanálisis y otras obras (19371939). Buenos Aires: Amorrortu.

HERRERA GÓMEZ, Coral (2010) La construcción sociocultural del amor romántico, Madrid: Fundamentos.

LUHMANN, Niklas (1985) El amor como pasión, Barcelona, Península.

MIGUEL, Jesús (1996) "Georg Simmel: La construcción social del género femenino como subcultura" en Mujeres y hombres en la formación de la teoría sociológica, Colección Academia, Madrid: Centro de Investigaciones Sociológicas.

ONRUBIA, J. (1997) "El papel de la escuela en el desarrollo adolescente”, en Eduardo MARTÍ y Javier ONRUBIA (Coord.): Psicología del desarrollo: el mundo del adolescente. Barcelona: Ice /Horsori.

PIAGET, Jean (1947) La psicología de le inteligencia, Buenos Aires: Psique.

SIMMEL, Georg (1988) La aventura, Barcelona: Península. 